\title{
Fabrication of bulk heterojunction solar cells by a modified spray-mist coating method
}

\author{
J.-h. Lee ${ }^{1}$, S. Yoshikawa ${ }^{2}$ and T. Sagawa ${ }^{1}$ \\ ${ }^{1}$ Graduate School of Energy Science, Kyoto University \\ Yoshida-honmachi, Sakyo-ku, 606-8501 Kyoto (Japan) \\ Phone: +81 75753 4871, e-mail: leemin@iae.kyoto-u.ac.jp, sagawa.takashi.6n@kyoto-u.ac.jp \\ ${ }^{2}$ Institute of Advanced Energy, Kyoto University \\ Gokasho, Uji, 611-0011 Kyoto (Japan) \\ Phone: +81 77438 4580, e-mail: s-yoshi@iae.kyoto-u.ac.jp
}

\begin{abstract}
.
The modified spray-mist coating method, which can fabricate thin films for organic photovoltaics (OPVs) by using ultrasonic deposition technique, is applied. This new method has a distinguishable merit, which enable us to roll-to-roll and pattern targeted aperture area. However, the modified spray-mist coated layer also has morphology with defects such as loosely linked droplets and pin-holes, like spray coating. Herein, we examined the basic characteristics of the modified spray-mist coating method as fine channel mist spray deposition and improved a method to maximize the OPV performance by thermal and additional solvent annealing.
\end{abstract}

\section{Key words}

organic thin-film solar cell, polythiophene, fullerene, bulk heterojunction, spray coating

\section{Introduction}

Recent progress in the power conversion efficiencies of OPVs has brought renewed attention to the possibility of practical use as the modules with large area. Spin-coating is one of the widely prevailed fabrication methods in the research field of OPVs because of its high precision and reproducibility. However, there is inherently a large amount of waste materials during the coating process. In this context, spin coating method is not desirable for rollto-roll process. Other solution processes recently used for the fabrication of OPVs, such as screen printing, doctor blading, and spray coating, are compatible with roll to roll or large manufacturing. In the present work, we demonstrate the implementation of the modified spraymist coating technology for fabrication of an organicbased bulk heterojunction solar cell. The modified spraymist coating method utilizes atomized droplets by ultrasonic generator, which is commonly known as a commercial ultrasonic humidifier or diffuser. It is plausible to be applied for large scale fabrication of polymer based solar cells. In addition, the modified spray-mist coating technology allows to pattern on the targeted area easily.
This is critical, for instance, for fabricating a monolithic photovoltaic device that is integrated and connected to one large module. This modified spray-mist coating method is a simple coating method, in which the liquid solution is ultrasonically atomized and the aerosol droplets are transferred onto the substrate by carrier gas. This method is a modification of an applied version of chemical vapor deposition (CVD), which is a chemical process used to produce high-purity, high performance in the semiconductor industry for thin films. However, in our experiment, the modified spray-mist coating method is different from CVD since the fine channel mist deposition process consists of the donor and/or acceptor spray coating by gas pressure without chemical reaction of the precursors. We investigated the basic and optical morphology and optimized this method to fabricate a well-performed solar cell with reproducibility.

\section{Experimental}

In the preparation of solar cell devices, indium-tin-oxide (ITO) coated glass substrates (Geomatec, $5 \Omega \mathrm{cm}^{-2}$ ) were first patterned by etching and then cleaned thoroughly with a sequence of solvents: detergent, deionized water, acetone and isopropanol, for $10 \mathrm{~min}$ each in an ultrasonic bath. Solutions of the active layer components, P3HT(Rieke Metal) and PCBM(Nano C), were prepared separately with a concentration of $8 \mathrm{mg} \mathrm{ml}^{-1}$ in chlorobenzene and stirred in ultrasonic bath at $50{ }^{\circ} \mathrm{C}$ for $2 \mathrm{~h}$. These solutions of active layer components were each loaded to its corresponding ultrasonic bottle for mist generation. We prepared a 1:0.8 mixture of P3HT and PCBM dissolved in chlorobenzene for a single channel deposition. The ultrasonic transducer produces vibration with 6 oscillators in the water. The solution was atomized by the ultrasonic transducer $(2.9 \mathrm{MHz})$ and the aerosols formed were transferred with the nitrogen carrier gas at a flow rate of $4 \mathrm{~L} \mathrm{~min}^{-1}$. The mixed aerosols in the nozzle were finally supplied through the linear source nozzle onto the heated substrate at a rate of $1.2 \mathrm{~mL} \mathrm{~min}^{-1}$. The substrate temperature was fixed at $110{ }^{\circ} \mathrm{C}$ and the number of coating exposures was set to 10 times after the 
surface morphology investigation in the pretest. The stage was moved at a constant rate of $1 \mathrm{~mm} \mathrm{~s}^{-1}$. The distance of the nozzle from the substrate was $1 \mathrm{~mm}$. An additional solvent mist spray coating was done by spraying DCB onto the active layers at a rate of $100 \mu \mathrm{lmin}^{-1}$ at ambient temperature. The active layer was then allowed to dry for about $10 \mathrm{~s}$. Thermal annealing was performed at $150{ }^{\circ} \mathrm{C}$ in a glove box. Lithium fluoride $(1 \mathrm{~nm})$ and aluminum $(100 \mathrm{~nm})$ were deposited by thermal evaporation in ultrahigh vacuum at $5 \times 10^{-3} \mathrm{~Pa}$. The photovoltaic characteristics were measured under nitrogen atmosphere using an Agilent 4156C parameter analyzer under AM1.5G (100 mW cm $\left.\mathrm{cm}^{-2}\right)$ simulated illumination using a solar simulator with a $1000 \mathrm{~W}$ xenon arc lamp.

\section{Results and Discussion}
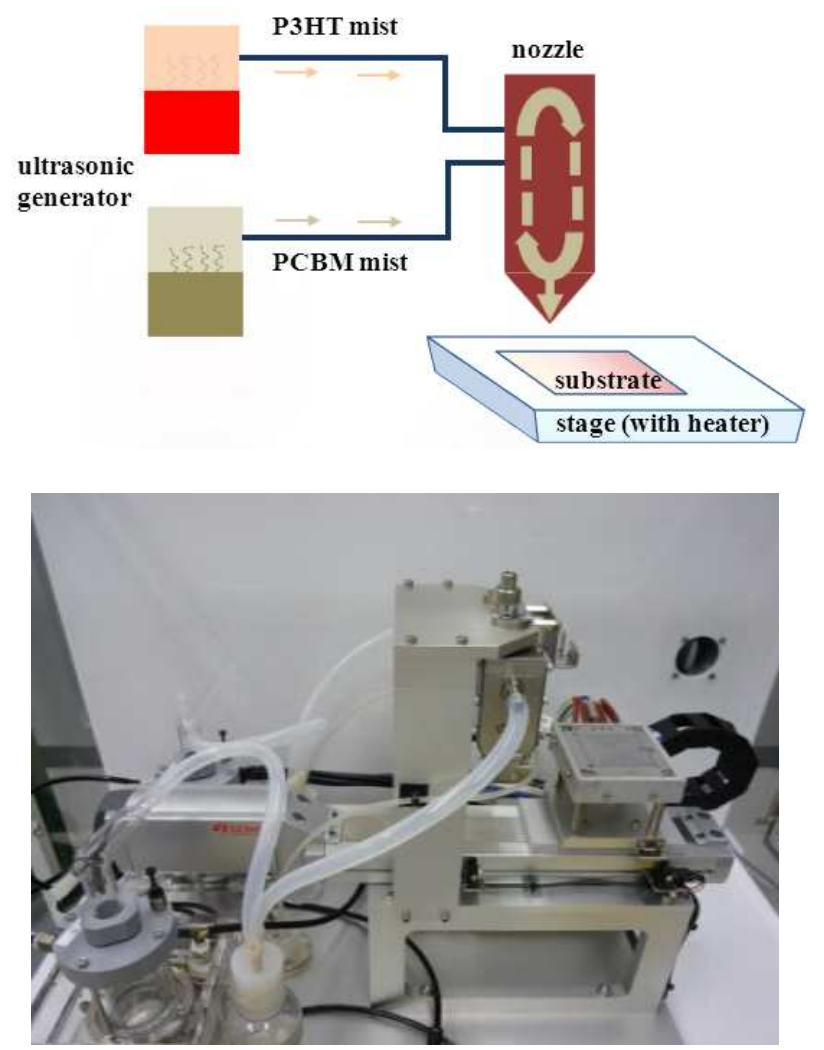

Fig. 1 Schematic illustration of the modified spray-mist coating process (above) and a picture of the apparatus (bottom). The donor (P3HT) and acceptor (PCBM) solutions are atomized in two separate mist sources as fine channel mist spray deposition (FCMSD)

Figure 1 shows a schematic illustration of the modified spray-mist coating (FCMSD) apparatus in our experiment [1]. The flow rate is controlled by the carrier gas $\left(\mathrm{N}_{2}\right)$. The donor (P3HT) and acceptor (PCBM) solutions are changed to tiny droplets in two separate mist sources. The fog or mist from the two sources is transferred to the nozzle along a plastic tube. The heated substrate moves on the stage repeatedly and accurately. The device performance of deposited films was investigated based on the common device configuration: glass-ITO (Indium Tin Oxide)/PEDOT:PSS(Poly(3,4ethylenedioxythiophene)poly (styrenesulfonate))/P3HT:PCBM/LiF/Al. The film is formed by the spreading of droplets and the combining of adjacent droplets. The film morphology usually depends on the properties of the solution such as vapor pressure, boiling point, surface tension as well as the flux of the droplets and ambient condition [2]-[8]. In the FCMSD method, the flux of the solution is the most influential factor because of the short distance between the nozzle and the substrate. In our experiment, the moving substrate was kept to $110^{\circ} \mathrm{C}$ to allow the active layer to have the better morphology. Many droplets are accumulated rapidly and lead to liquid phase below 100 ${ }^{\circ} \mathrm{C}$. The high temperature enables that the quality of layers is reproducible and under control. Even though this high drying temperature affect badly to the forming of an well-established crystallite in the active layer [3], [9]-[11], the damage is recovered by the DCB additional solvent coating [1],[7]. The DCB additional solvent coating leads to dissolve the uneven and rough surface which was attributed to fast drying.

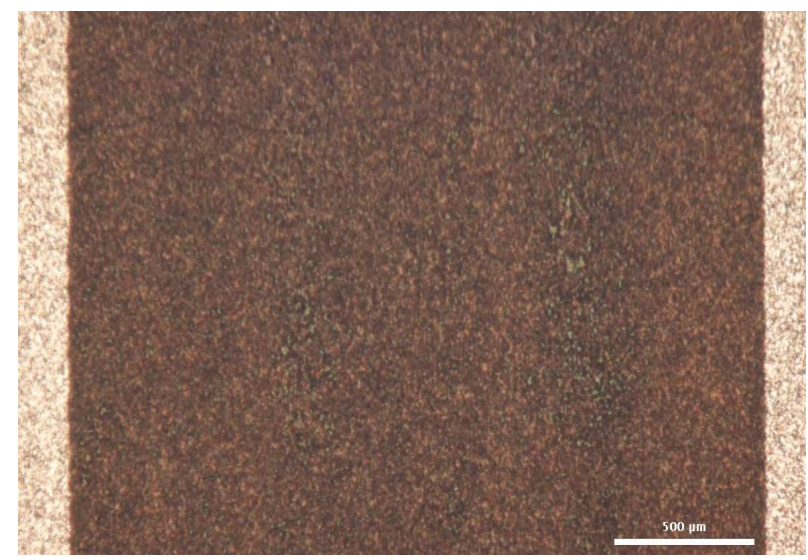

Fig. 2 Optical image of the common device configuration:glassITO/PEDOT:PSS(spin coating)/P3HT-PCBM(FCMSD)/LiF/Al.

To look into the morphology of the surface after FCMSD coating, we investigated the surface of a specific area where $\mathrm{Al}$ was coated. The $\mathrm{Al}$ on the back reflects the light and shows the some defect and pin-hole on the surface easier. Even though DCB additional solvent coating was sprayed, the perfect layer without pin-holes is obtained hardly like Figure 2, considering the principle of being coated on the substrate. In this respect, we should take into account the optimal thickness, for both transportation of carriers and prevention of defects. Because the active layer is formed by the accumulation of dried droplets, an optimal active layer is comparatively thick. Too thin active layer cannot cover pinholes and cracks which are formed by dried droplets [12],[13]. In addition to the thicker active layer, the additional DCB coating is applied to build proper carrier path and connect the isolated droplets. Finally, it was found that the minimum thickness of the active layer for stable and reproducible performance was around $300 \mathrm{~nm}$ after the additional DCB solvent coating. In previous report, we show the optimal thickness of active layer can be flexible according to the main coating process [13].

(a) 


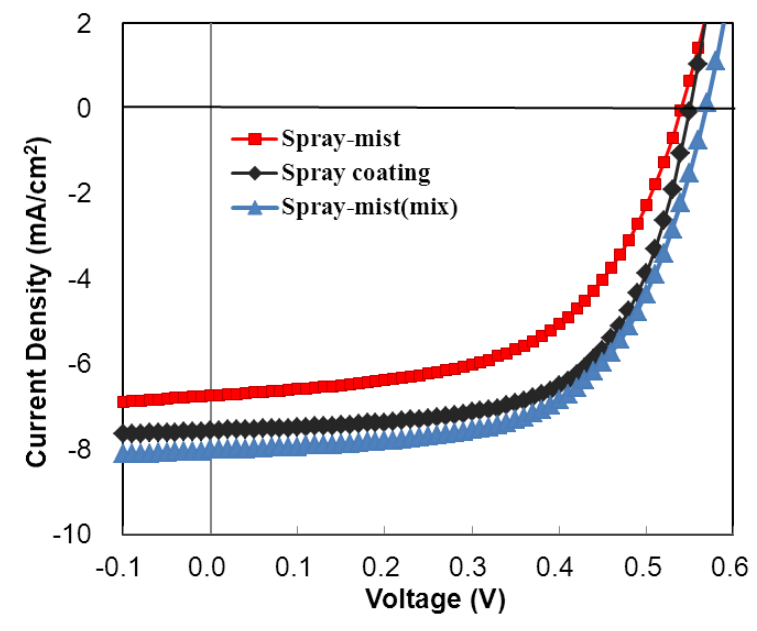

(b)

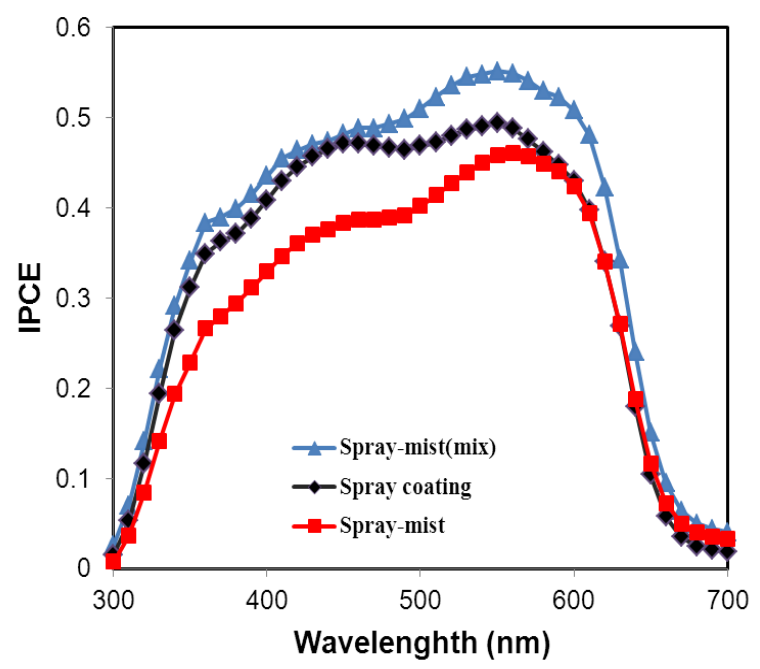

Fig. 3 (a) J-V characteristic of devices of glass-ITO/PEDOT:PSS /P3HT:PCBM/ additional DCB solvent coating/LiF/Al (100 mW $\mathrm{cm}^{-2}$, AM 1.5G) with a different coating method. (b) IPCE comparison of three devices according to coating method.

In Figure 3(a), we compare the J-V characteristic of three devices with different coating method. Among the two devices by the modified spray-mist coating method, one utilize only a single channel for blended P3HT/PCBM (triangle) and the other one is fabricated by two separate channel for each donor and acceptor (rectangle). It is compared by spray coated device with the same structure and thickness (diamond). The device fabricated from two separate channel has $V_{o c}=0.54, J_{s c}=6.75 \mathrm{~mA} / \mathrm{cm}^{2}, F F=$ 0.56 and $E_{f f}=2.03 \%$. Notably, the $J-V$ characteristic of the device used one single channel $\left(V_{o c}=0.57, J_{s c}=\right.$ $8.02 \mathrm{~mA} / \mathrm{cm}^{2}, F F=0.60$ and $\left.E_{f f}=2.75 \%\right)$ are similar to the performance of spray coated device. This value is also compatible to the performance of spin coated one fabricated in air, even if it is not shown here [7]. It is thought that the additional DCB solvent annealing method compensate for losses which would result from a hot substrate.

Figure 3(a), (b) show that the two channel system is not enough to blend the donor and acceptor totally in the space of nozzle. Moreover, the low electrical characteristic in two channel system may come from the unbalanced deposition caused by the density gap of donor and acceptor. It is known that the density of PCBM $(1.50 \mathrm{~g}$ $\left.\mathrm{cm}^{-3}\right)$ is larger than the one of P3HT $\left(1.10 \mathrm{~g} \mathrm{~cm}^{-3}\right)$ [14],[15]. The PCBM has higher solubility in chlorobenzene than P3HT, so the dried PCBM droplets are lifted up by a rising current air from the hot substrate. It leads to the separation of P3HT and PCBM in the coating process. Finally, this phenomenon restricts the formation of proper BHJ nanostructure.

\section{Conclusion}

We have investigated the possibility of the application of new coating method, called the modified spray-mist coating technique. The new system need to be refined and updated continuously to solve some problems like unbalanced deposition and loss of the solution. Moreover, the efforts for less use of donor/acceptor materials should be accompanied for cost reduction. However, since the apparatus can be controlled and manipulated reproducibly and accurately, we expect the new technique will be a simple alternative for some largescale manufacturing production.

\section{Acknowledgement}

The authors are grateful to Dr. Yoshio Masuda (TOUKI Co. Ltd.) for his advice on the design and manufacturing of the modified spray-mist coating apparatus. This work is partially supported by the New Energy and Industrial Technology Development Organization (NEDO) of the Ministry of Economy, Trade, and Industry (METI), Core Research of Evolutional Science \& Technology Agency (CREST) from Japan Science Technology Agency (JST), and the Global Center of Excellence (GCOE) Program of Kyoto University from the Ministry of Education, Culture, Sports, Science and Technology (MEXT) in Japan.

\section{References}

[1] J. Lee, T. Sagawa, S. Yoshikawa, "Fast screening of an optimal ratio of polymer: fullerene mixture for organic solar cells by novel coating method", Energy Technology, 2013, Vol.1, pp. 85-93.

[2] B.-K. Yu, D. Vak, J. Jo, S.-I. Na, S.-S. Kim, M.-K. Kim, D.-Y. Kim, "Factors to be Considered in Bulk Heterojunction Polymer Solar Cells Fabricated by the Spray Process", IEEE J. Select. Topics Quantum Electron., 2010, vol 16, pp. 1838-1846.

[3] D. Vak, S.-S. Kim, J. Jo, S.-H. Oh, S.-I. Na, J. Kim, D.-Y. Kim, "Fabrication of organic bulk heterojunction solar cells by a spray deposition method for low-cost power generation", Appl. Phys. Lett., 2007, vol 91, pp. 081102.

[4] T. Matsutani, K. Yamamoto, "Solvent Annealing Induced Perpendicular Orientation of Cylindrical Microdomains in Polystyrene- b -poly(4-hydroxyl styrene)/PEG Oligomer Blend Thin Film Made by Spin-coating from Selective Solvent", J. Phys.: Conf. Ser., 2011, vol 272, pp. 012015.

[5] R. Green, A. Morfa, A. J. Ferguson, N. Kopidakis, G. Rumbles, S. E. Shaheen, "Performance of bulk heterojunction photovoltaic devices prepared by airbrush 
spray deposition", Appl. Phys. Lett., 2008, vol 92, pp. 033301.

[6] H.-Y. Park, K. Kim, D. Y. Kim, S.-K. Choi, S. M. Jo, S.-Y. Jang, "Facile external treatment for efficient nanoscale morphology control of polymer solar cells using a gasassisted spray method", J. Mater. Chem., 2011, vol 21, pp. 4457-4464.

[7] J. Lee, T. Sagawa, S. Yoshikawa, "Morphological and topographical characterizations in spray coated organic solar cells using an additional solvent spray deposition", Org. Electron., 2011, Vol. 12, pp. 2165-2173.

[8] K. X. Steirer, M. O. Reese, B. L. Rupert, N. Kopidakis, D. C. Olson, R. T. Collins, D. S. Ginley, "Ultrasonic spray deposition for production of organic solar cells", Solar Energy Materials and Solar Cells, 2009, vol 93, pp. 447-453.

[9] Y. Liang, D. Feng, Y. Wu, S.-T. Tsai, G. Li, C. Ray, L. Yu, "Highly Efficient Solar Cell Polymers Developed via Fine Tuning of Structural and Electronic Properties", Journal of the American Chemical Society, 2009, vol 131, pp. 77927799.

[10] L. Chang, H. W. A. Lademann, J.-B. Bonekamp, K. Meerholz, A. J. Moulé, "Effect of Trace Solvent on the Morphology of P3HT:PCBM Bulk Heterojunction Solar Cells", Advanced Functional Materials, 2011, vol 21, pp. 1779-1787.
[11] G. Li, Y. Yao, H. Yang, V. Shrotriya, G. Yang, Y. Yang, "Solvent Annealing" Effect in Polymer Solar Cells Based on Poly(3-hexylthiophene) and Methanofullerenes", Advanced Functional Materials, 2007, vol 17, pp. 16361644.

[12] J. Alstrup, M. Jørgensen, A. J. Medford, F. C. Krebs, "Ultra Fast and Parsimonious Materials Screening for Polymer Solar Cells Using Differentially Pumped Slot-Die Coating", ACS Appl. Mater. Interfaces, 2010, Vol. 2, pp. 2819-2827.

[13] J. Lee, T. Sagawa, S. Yoshikawa, "Thickness dependence of photovolatic performance of additional spray coated solar cells", Thin solid Films, in press (doi:10.1016/j.tsf.2012.07.080).

[14] T. J. Prosa, M. J. Winokur, J. Moulton, P. Smith, A. J. Heeger, "X-ray structural studies of poly(3alkylthiophenes): an example of an inverse comb", Macromolecules, 1992, Vol. 25, pp. 4364-4372.

[15] C.W.T Bulle-Lieuwma, W.J.H.van Genip, J.K.J. van Duren, P. Jonkheijm, R.A.J. Janssen, J.W. Niemantsverdriet, "Characterization of polymer solar cells by TOF-SIMS depth profiling", Appl. Surf. Sci., 2003, Vol.203,pp.547-550. 